\title{
Neck Circumference as a Screening Measure for Abdominal Obesity and its Association with Metabolic Syndrome among High Risk Filipino Patients in Makati Medical Center - a Pilot Study
}

\author{
Nerissa S. Ang and Josephine Carlos Raboca \\ Section of Endocrinology, Diabetes and Metabolism, Makati Medical Center
}

\begin{abstract}
Objectives. The study aims to determine the cut off level of neck circumference that would correlate with abdominal obesity, using waist circumference as the gold standard; and determine its relationship with metabolic syndrome among high risk filipino patients.

Methods. A total of 425 high risk Filipino patients who sought consult at Makati Medical Center from the period of March to October 2010 were qualified to participate in the study. Pertinent history, including blood pressure measurement and anthropometric measurements such as height, weight, neck circumference and waist circumference were recorded; after an 8 hour overnight fast, blood samples were sent for fasting plasma glucose, HDL cholesterol and triglyceride levels.

Results. Neck circumference cut off levels of $\geq 40 \mathrm{~cm}$ for males and $\geq 33.8 \mathrm{~cm}$ for females showed a low sensitivity and moderately high specificity for determining patients with abdominal obesity; $62.07 \%$ and $90.09 \%$ for males, $67.59 \%$ and $85.56 \%$ for females, respectively. In terms of determining patients with metabolic syndrome, it has a low sensitivity and specificity. However, obese by neck circumference cut off levels showed significant association $(p$ value $<0.001)$ with the component risk factors of metabolic syndrome, except for hypertriglyceridemia. Likewise, neck circumference also showed a strong positive linear relationship with waist circumference.
\end{abstract}

Conclusion. Neck circumference showed a strong correlation with abdominal obesity, as well as with the component risk factors of metabolic syndrome, and therefore with risk of cardiovascular disease. Above the NC cut off levels, its predictive value for abdominal obesity is high; however, it has a poor ability to detect patients with abdominal obesity in the general population and therefore, cannot be used as a screening test.

Keywords: neck circumference, waist circumference, metabolic syndrome, obesity

\section{Introduction}

Obesity is emerging as a health epidemic around the world. According to the Center for Disease Control and Prevention, obesity is rapidly spreading across all regions and demographic groups. ${ }^{1-2}$ Obesity is a hallmark of affluence as seen in its high prevalence rate among industrialized countries. This trend is starting to change with recent survey results suggesting obesity is becoming common among children and adults in developing countries like the Philippines. According to the latest survey conducted by the Food and Nutrition Research Institute of the Department of Science and Technology (FNRI-DOST), they found that obese Filipino women outnumber the men. Those most at risk of being obese are 40-59 year-old adults. ${ }^{3}$ While obesity and overweight may not be relatively as high in the Philippines compared to US

ISSN 0857-1074

Copyright $(0) 2011$ by the JAFES

Received July 6, 2011. October 5, 2011.

*Presented Poster Communication Series, $20^{\text {th }}$ Annual Convention American

Association of Clinical Endocrinologists, San Diego, California, April 14, 2011

*Presented at the Philippine Research Initiatives on Diabetes and Endocrinology

(PRIDE), 2011 PSEM Annual Convention, Edsa Shangri-La Hotel, March 16, 2011

*Presented at Poster Free Communication Series PLAS-PFIZER LIPID Research,

Crowne Plaza Galleria, Manila February 11, 2011 trends, a recent study that assessed the prevalence of the metabolic syndrome (MS) in the Philippines found that abdominal obesity was seen in approximately $17.7 \%$ of Filipino men and $35.1 \%$ of Filipino women in the study. ${ }^{4}$ Various studies have shown that obesity is associated with increased risk of coronary heart disease, diabetes, hypertension and other chronic degenerative diseases. . $^{3,13}$

MS is a clustering of several metabolic factors that increases the risk for atherosclerotic cardiovascular disease (ASCVD) and diabetes mellitus (DM). These factors include dysglycemia, high blood pressure, elevated triglyceride levels, low high-density lipoprotein (HDL) cholesterol levels and obesity, in particular central adiposity. ${ }^{4,14}$ Since the first official definition of the MS put forward by a working group of the World Health Organization (WHO) in 1999, a number of different

Corresponding author: Nerissa S. Ang, M.D.

$2079^{\text {th }}$ Avenue (East), B. Serrano St., Caloocan City, Philippines 1400

Tel No. $+6329852503 ;+639273703437$

Fax No..: +6323611147

E-mail:nsang23@yahoo.com 
definitions have been proposed. Although MS has several definitions, including those by the International Diabetes Federation (IDF) and the National Cholesterol Education Program-Adult Treatment Panel III (NCEP-ATP III), for the purpose of this study we will be using the criteria modified by the American Heart Association/National Heart, Lung and Blood Institute (NCEP/ATP IIIAHA/NHLBI). Using this criteria, the prevalence of MS in the general population in the Philippines in 2003 to 2004 for adults aged 20 years and above, representing 42.6 million Filipinos, was $18.6 \% .^{4}$

In 1999 the WHO definition of MS included a measure of obesity and defined obesity in terms of either body mass index (BMI) or waist-to-hip ratio (WHR). The latest definition is the one of the International Diabetes Federation (IDF), which takes into account evidence that abdominal obesity is the important component of the metabolic syndrome ${ }^{15}$ and proposed waist circumference as an indication of abdominal obesity. 5, 14, 16-19

A simple measurement of waist size is a valuable assessment tool for cardiovascular risk and a strong diagnostic criterion for MS according to a study done by James M. Rippe in collaboration with Weight Watchers International. Stronger relationships between waist size and HDL and total cholesterol to HDL ratio were found compared with BMI. The results confirmed the idea that abdominal fat is linked with higher risk than being generally overweight and also supported the use of BMI to assess overall risk. ${ }^{6}$

BMI and waist circumference (WC) are two commonly accepted anthropometric indices for predicting MS. Also some studies report that WHR identifies patients with abdominal obesity. However, WC has been suggested as being a more practical measure of abdominal fat mass and total body fat and is more closely correlated with abdominal adipose tissue than WHR.5-6, 17-21 In a study by Wang (2008) in a Chinese population aged 18-85 in China, a comparative validation of three body stature measures, WC, BMI and WHR were done to define which among the 3 measurements is most closely predictive of the nonadipose components of the IDF definition of MS. The study showed that WC is best able to discriminate MS, and is a better predictor than BMI in men. WHR in both sexes is a much weaker predictor. ${ }^{5}$

Jean Vague was the first to show that different body morphologies or types of fat distribution are related to the health risks associated with obesity. He used a neck skin fold in his index of masculine differentiation to assess upper body fat distribution. ${ }^{22}$

Although obesity results in metabolic abnormalities, upper-body obesity is more strongly associated with glucose intolerance, hyperinsulinemia, diabetes, hypertriglyceridemia, gout, and uric calculous disease than is lower-body obesity. ${ }^{7,} 22-25$ It is believed that the association of abdominal obesity with cardiovascular disease (CVD) risk factors of the MS was due to accumulation of visceral fat volume. In 2005, the IDF proposed a unified worldwide definition of the MS. In this definition, central obesity was regarded as a prerequisite and incorporated element with different WC cut offs by gender and ethnicity, in which WC of $90 \mathrm{~cm}$ and $80 \mathrm{~cm}$ was set for Asians using the IDF worldwide definition of MS. ${ }^{16}$

Waist circumference will be used as the gold standard in this study to determine patients with abdominal obesity, and thus consequently increased their risk for MS. In newly published data by Salomon, et. al., they showed that among males and females, visceral fat thickness showed a strong and significant correlation with WC, and a weak but significant correlation with MS. For males, the minimum visceral fat thickness associated with MS was $17.70 \mathrm{mms}$, with a mean of $59.39 \mathrm{mms}$, and the minimum WC associated with MS was $82.50 \mathrm{cms}$ with a mean of 99.74 cms. For females, the minimum visceral fat thickness associated with MS was $10.70 \mathrm{mms}$, with a mean of $47.77 \mathrm{mms}$, and the minimum WC was $78.00 \mathrm{cms}$, with a mean of $92.68 \mathrm{cms} .{ }^{26}$ The study involved 311 patients aged 40-65 years old who were admitted in the executive health check-up program at the Makati Medical Center. WC was taken as the circumferential measurement of the area at the midpoint between the lower border of the last rib and the iliac crest. MS was defined according to the 2009 revised criteria proposed by the International Diabetes Federation (IDF), World Heart Federation, International Atherosclerosis Society and National Heart, Lung and Blood Institute (NHLBI). ${ }^{14}$ Likewise, in the study by Balkau, et al, WC was used as a measure of abdominal adiposity because of the close correlation between WC and the amount of intra-abdominal fat observed by computed tomography. ${ }^{9}$

Neck circumference (NC), an index of upper-body subcutaneous adipose tissue distribution, was evaluated in relation to cardiovascular (CV) risk factors by Sjo "stro " $\mathrm{m}$ et al. The neck and thigh circumferences were used as indices of upper- and lower-body subcutaneous tissue distribution, respectively, in a three compartment body composition model. This model of interpretable anthropometry consisted of the visceral and subcutaneous adipose tissue masses as well as the lean body mass. Even after adjusting for these body compartments, NC, an index of upper-body subcutaneous adipose tissue distribution, was positively related to most $\mathrm{CV}$ risk factors. At the same time, thigh circumference was negatively related to the risk factors. ${ }^{25}$

All evidence suggests that abdominal fat carries a higher health risk than peripheral fat, and that the visceral fat component correlates the most strongly with increased risk. Whereas computed tomography and magnetic 
resonance imaging allow more precise measurement of abdominal fat, they are impractical for routine clinical use.

Several tools that can be used to assess overweight and obesity at primary care facilities include measurements of weight, height, waist and hip circumferences, and calculations of WHR and BMI. However, it is not always practical to use these techniques, especially in busy everyday primary care practice. Such is the case in the local setting, particularly in community health centers and barangays; where physicians and nurses are very limited while patients are one too many. Some techniques would necessitate longer time; even requiring removal of one's clothes in front of strangers, which in a conservative society such as ours, would not be very comfortable and would be frowned upon. And, as previously stated, other procedures such as ultrasound, computed tomography and magnetic resonance imaging are expensive and are primarily used for research purposes.

As a first step to achieve obesity control, it is important to develop a reliable, simple and quick method for the assessment of obesity in primary care clinics in the local setting. NC, an index of upper body obesity, is a simple screening measure that can be used to identify patients who have abdominal obesity.

In a previous study done by Liubov (Louba) and Laor in a family medicine clinic in Israel in 2001, NC as an index of upper-body obesity was found to be a simple and timesaving screening measure that can be used to identify overweight and obese individuals. ${ }^{23}$

Furthermore, in patients who are not ambulatory and cannot tolerate standing position, especially in patients admitted in intensive care units where height and weight measurements cannot be done, NC measurements can take their place. There are also limited epidemiological studies on the clinical significance of NC with regards to its association with obesity and increased risk of $\mathrm{CV}$ risk factors that would require a more comprehensive evaluation of their overweight and obesity status.

The purpose of the study is to determine whether measurement of neck circumference (NC) can correlate well with waist circumference measurement. And if so, can it be used as a screening test for identifying patients with abdominal obesity? The study also aims to establish its' association with metabolic syndrome and its' component risk factors and to define the cut off levels of neck circumference that would identify patients with abdominal obesity.

\section{Patient and Methods}

\section{Patient Population}

An observational, analytical, cross-sectional study was done. Sample population included high risk Filipino patients who were admitted at Makati Medical Center for any reason from the period of March 1 to October 31, 2010.
Patients were selected using simple random sampling by lottery method. Using the daily list of hospital admissions, each patient was assigned a unique number. The numbers were placed in a bowl, mixed thoroughly and patients were randomly handpicked by the researcher. Inclusion and exclusion criteria were followed. High risk patients included those patients who were at high risk for obesity or with increased risks for cardiovascular disease. He or she may satisfy any one of the following inclusion criteria: adults > 18 years of age; with strong family history for premature coronary artery disease (CAD) (first degree relative with CAD by age 45 years old or younger) or presence of any one of the components of MS defined as: $W C \geq 90 \mathrm{~cm}$ in men or $\geq 80$ $\mathrm{cm}$ in women; triglycerides (TG) $\geq 150 \mathrm{mg} / \mathrm{dl}$ or on treatment; HDL $<40 \mathrm{mg} / \mathrm{dL}$ in men or $<50 \mathrm{mg} / \mathrm{dL}$ in women or on treatment; blood pressure (BP) $\geq 130 \mathrm{mmHg}$ systolic and $\geq 85 \mathrm{mmHg}$ diastolic and fasting plasma glucose $(\mathrm{FPG}) \geq 100 \mathrm{mg} / \mathrm{dL}$, which includes type $2 \mathrm{DM}$. Excluded were those patients with known major medical conditions, active inflammatory and neoplastic disease; established CVD (previous myocardial infarction (MI), stroke or CAD) or with known thyroid dysfunction, thyroid mass or nodules or any neck mass. A written informed consent was obtained from all qualified study subjects.

\section{Methods}

A total of 425 patients, 224 patients with abdominal obesity and 201 patients without abdominal obesity were qualified to participate in the study. Abdominal obesity was defined as waist circumference (WC) $\geq 90 \mathrm{~cm}$ in men or $\geq 80 \mathrm{~cm}$ in women.

Anthropometric evaluation was performed only once by the investigator during the patient's hospital stay before the first meal of the day. To minimize inter-observer variability, all measurements were done by the investigator. Body height and body weight were recorded to the nearest $0.5 \mathrm{~cm}$ and $0.1 \mathrm{~kg}$, respectively using properly calibrated Detecto ${ }^{\circ}$ scales. Measurement of the weight was done on an empty bladder, with the patient standing barefoot at the center of the platform, unassisted wearing minimal clothing. Minimal clothing is defined as a single layer of thin clothing, excluding jeans or heavy apparels. Height was measured with shoulders relaxed, shoulder blade, buttocks and heels touching the board, feet flat and heels almost together and on barefoot. Waist and neck circumference measurements were done using a standard non-stretchable plastic tape measure, which was used for the entire duration of the study. WC was measured to within $1 \mathrm{~mm}$ at the waist midway between the lowest rib and the iliac crest, with the patient standing at the end of gentle expiration. NC was measured at the level of the cricoid cartilage in women, mid-neck height, between the mid-cervical spine to mid-anterior neck, to within $1 \mathrm{~mm}$. In men with a laryngeal prominence (Adam's apple), NC was measured just below the 
prominence. ${ }^{22-24}$ All circumferences were taken with the subjects standing upright, shoulders relaxed and facing the author. BMI was derived from body weight in kilograms divided by the square of body height in meters. Data collected include demographic information and a brief medical history.

Blood pressure was measured twice using ALPK2® nonmercurial sphygmomanometer with the arm supported at heart level after sitting quietly for 10 minutes. The systolic BP was defined as the appearance of the first sound (Korotkoff phase 1) and diastolic BP was defined as the disappearance of the sound (Korotkoff phase 5) during deflation of the cuff. There was at least a 30 second interval between the two separate measurements and thereafter the mean of the two measurements was considered as the participant's BP.

Blood samples were drawn from the antecubital vein, after at least 8 hours of overnight fasting. Blood samples were sent to the laboratory of clinical biochemistry at Makati Medical Center for analyses of blood glucose, serum triglycerides and HDL-cholesterol on a Cobas ${ }^{\circledR}$ automated clinical chemistry analyzer by means of standard biochemical procedures.

\section{Definition of Terms}

According to the modified criteria by the American Heart Association/National Heart, Lung and Blood Institute (NCEP/ATP III-AHA/NHLBI), MS is defined as the presence of any 3 of the following 5 features: $W C \geq 90 \mathrm{~cm}$ in men or $\geq 80 \mathrm{~cm}$ in women; $\mathrm{TG} \geq 150 \mathrm{mg} / \mathrm{dl}$ or on treatment; $\mathrm{HDL}<40 \mathrm{mg} / \mathrm{dL}$ in men or $<50 \mathrm{mg} / \mathrm{dL}$ in women or on treatment; $\mathrm{BP} \geq 130 \mathrm{mmHg}$ systolic and $\geq 85$ $\mathrm{mmHg}$ diastolic and FPG $\geq 100 \mathrm{mg} / \mathrm{dL}$, which includes those diagnosed with type $2 \mathrm{DM}$ or on treatment. ${ }^{4}$

Abdominal obesity is defined as WC of more than or equal to $90 \mathrm{~cm}$ in men or more than or equal to $80 \mathrm{~cm}$ in women.

Under the Asia Pacific Guidelines for the classification of obesity ${ }^{26}$, a BMI of less than or equal to 18 is classified as underweight; 18-22.9 is normal, 23-24.9 is overweight, 2529.9 is obese class 1 , and a BMI of more than or equal to 30 is under obese class 2 .

\section{Statistical Analysis}

Continous data were expressed as means and standard deviations, and differences in means were tested using two-sided $t$ tests. The differences of categorical data in different groups were compared using Pearson's Chisquare tests. Likelihood estimates (OR) and 95\% confidence intervals (CI) were obtained by use of logistic regression analyses in models that adjusted for sex, age and other confounders. Receiver operating characteristic (ROC) curve analysis combined with canonical discriminant functions analysis was employed to determine optimal sex-specific cut-off levels of NC in relation to abdominal obesity. The optimal cut-off points were determined by the point of convergence of sensitivity and specificity, by simultaneously maximizing the two. The Youden's Index $(J)$, the maximum potential effectiveness of a biomarker, is a summary measure of the ROC curve used in the study to determine the optimal sexspecific cut-off levels of neck circumference that would correlate with abdominal obesity.

The area under the ROC curve (AURC) was used as a general measure of discrimination of a predictor. A value of $p<0.05$ on the two-tail test was considered statistically significant.

\section{Results}

\section{Characteristics of the Study Population}

A total of 425 patients, 227 males and 198 females, participated in the study. Of the 425 patients, 224 patients were obese by abdominal circumference, while 201 patients were not obese by abdominal circumference. Table 1 depicts the demographic profile and clinical characteristics of the study population. The mean age of the study population was $49.35 \pm 11.26$ years with predominance of males over females. The study population belonging to the obese group were heavier, had a larger WC and a higher BMI. Most of the patients in the obese group fall under the obese class 1 classification (53.6\%, 120 out of 224 patients) as compared to the nonobese group, who are mostly classified under normal (39.3\%, 79 out of 201 patients).

The difference of the mean levels of fasting TG, although higher and slightly more frequent in the obese arm, was not statistically significant. Reduced HDL-cholesterol was observed to be more frequent in the obese group than in the non-obese group $(34.8 \%$ vs. $23.4 \%$, p value $<0.05)$. There were also more patients with elevated fasting plasma glucose or previously diagnosed with type 2 DM in the obese group ( $42 \%$ vs. $23.4 \%$, p value $<0.001)$. The mean BP of patients in the obese group was also higher at $126.29 \pm 12.71 / 82.28 \pm 7.26 \mathrm{~mm} \mathrm{Hg}, \mathrm{p}$ value $<0.001$. Consequently, more patients satisfied the criteria of metabolic syndrome in the obese group as compared to the non-obese group, $57.1 \%$ and $12.4 \%$ respectively. (Table 1 and 2)

\section{Cut off levels of NC for determining abdominal obesity using ROC analysis}

In the study population, $\mathrm{NC} \geq 40 \mathrm{~cm}$ for males and $\geq$ $33.8 \mathrm{~cm}$ for females were the best cut-off levels for determining patients with abdominal obesity (WC $\geq 90 \mathrm{~cm}$ in males $/ 80 \mathrm{~cm}$ in females) using ROC analysis with $62.07 \%$ sensitivity, $90.09 \%$ specificity and $75.77 \%$ accuracy for males and $67.59 \%$ sensitivity, $85.56 \%$ specificity and $75.76 \%$ accuracy for females. The optimal cut-off points 
Table1. Clinical characteristics of the study population

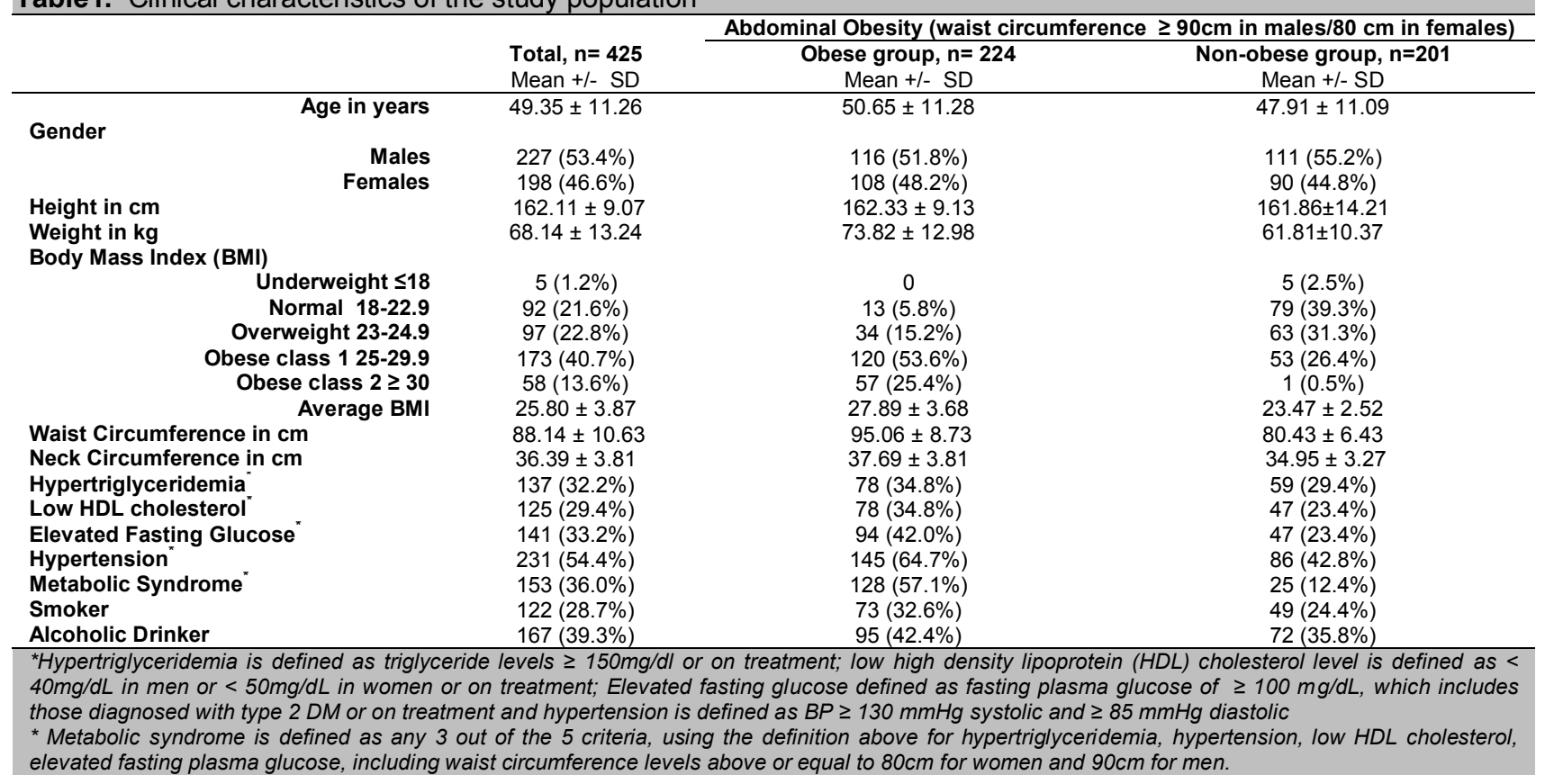

Table 2. Mean values of the metabolic risk factors of the study population

\begin{tabular}{|c|c|c|c|c|}
\hline & $\begin{array}{l}\text { Total, } \mathbf{n}=\mathbf{4 2 5} \\
\text { Mean }+/- \text { SD }\end{array}$ & $\begin{array}{c}\text { Obese group, } \mathbf{n}=\mathbf{2 2 4} \\
\text { Mean }+/-S D\end{array}$ & $\begin{array}{c}\text { Non-obese group, } \mathbf{n}=\mathbf{2 0 1} \\
\text { Mean }+/- \text { SD }\end{array}$ & $p$ value \\
\hline Fasting Triglycerides in $\mathrm{mg} / \mathrm{dL}$ & $137.53 \pm 80.08$ & $144.12 \pm 73.26$ & $130.19 \pm 86.63$ & 0.073 \\
\hline $\begin{array}{l}\text { High density lipoprotein } \\
\text { (HDL) cholesterol in } \mathrm{mg} / \mathrm{dL}\end{array}$ & $52.46 \pm 15.35$ & $50.85 \pm 15.66$ & $54.26 \pm 14.83$ & $<0.05$ \\
\hline Fasting plasma glucose in $\mathrm{mg} / \mathrm{dL}$ & $102.23 \pm 32.53$ & $106.58 \pm 37.63$ & $97.38 \pm 24.88$ & $<0.05$ \\
\hline Systolic Blood Pressure in $\mathrm{mmHg}$ & $123.81 \pm 13.78$ & $126.29 \pm 12.71$ & $121.04 \pm 14.40$ & $<0.001$ \\
\hline Diastolic Blood Pressure in $\mathrm{mmHg}$ & $80.99 \pm 8.01$ & $82.28 \pm 7.26$ & $79.55 \pm 8.56$ & $<0.001$ \\
\hline
\end{tabular}

were determined by the point of convergence of sensitivity and specificity, by simultaneously maximizing the two. The Youden's Index $(J)$, the maximum potential effectiveness of a biomarker, is a summary measure of the ROC curve that was used to determine the optimal NC cut off points. (Table 3) The receiver operating characteristic curve analysis was used for each neck circumference value by plotting the true positive rate (sensitivity) against the false positive rate (1-specificity) to determine the optimal cut off levels, area under the curve is 0.831 ( $p$ value $<0.001$ in both males and females). (Figure 1)

Logistic regression analysis showed that neck circumference if positive, has a good probability of determining abdominal obesity in both genders, for every 1 standard deviation increment in $\mathrm{NC}$, the unit odds ratio in males corresponded to 1.87, and 1.94 in females ( $\mathrm{p}$ value $<0.001$ ). (Figure 2) Neck circumference is a contributing factor to more than half of the variability of waist circumference and has a moderately strong positive linear relationship with waist circumference, $r=0.74$, $\mathrm{p}$ value $<$ 0.001. (Figure 3)

\section{Association of obese by NC and the individual components of MS}

Patients who are obese by NC, using cut off levels of more than or equal to $40 \mathrm{~cm}$ for males and $33.8 \mathrm{~cm}$ for females respectively, showed a significant correlation with low HDL-cholesterol level, high BP and elevated FPG or the presence of DM. Hypertriglyceridemia did not show significant relationship with NC. The odds of hypertension among patients who are obese, using NC $(\geq 40 \mathrm{~cm} / 33.8 \mathrm{~cm})$ as our parameter, is 1.8 times higher than those who are non-obese; as with low HDL-cholesterol which was found to be 2.05 times higher than non-obese. Likewise, type $2 \mathrm{DM}$ or elevated FPG of more than or equal to $100 \mathrm{mg} / \mathrm{dL}$ was associated significantly with a 2.28-fold increased likelihood among obese patients. In terms of BMI, patients who are obese using the Asia Pacific Guidelines (BMI of more than or equal to 25) showed a significant correlation with obese by NC, p value of $<0.001$. On the other hand, excluding the criteria of abdominal obesity, obese by NC showed a significant relationship with 2 out of the 4 components of MS, as well as 3 out of the 4 components of MS, namely: elevated fasting TG, hypertension, low HDL levels, and elevated FPG or the presence of type $2 \mathrm{DM}$, with $\mathrm{p}$ value of $<0.001$ and 0.001 , respectively. (Table 4 )

In our study, about $57.1 \%$ or 128 out of 224 patients classified with abdominal obesity (WC $\geq 90 \mathrm{~cm}$ in men or $\geq$ $80 \mathrm{~cm}$ in women) satisfied the criteria of MS. (Table 1) Among males, NC of $\geq 40 \mathrm{~cm}$ emerged as the optimal cutoff level for abdominal obesity, showing a predictive 

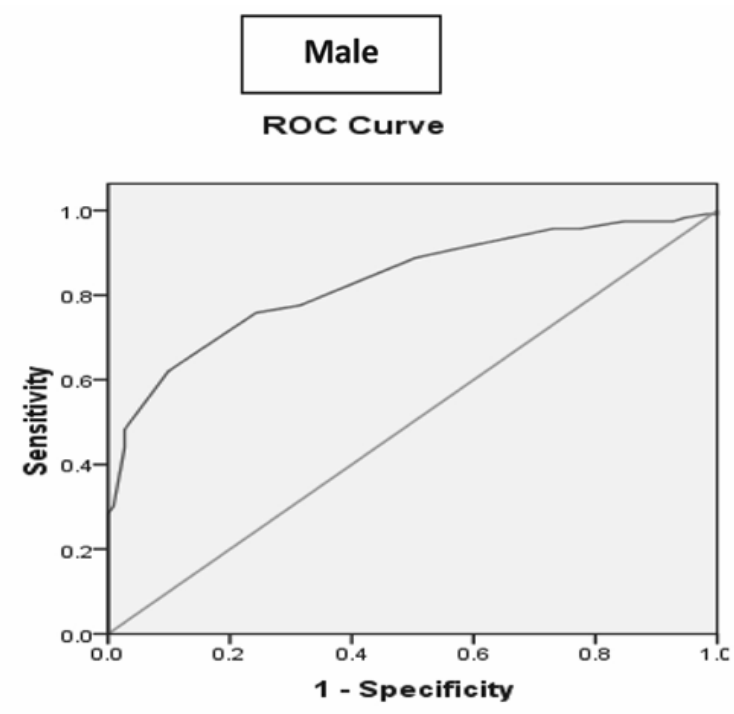

Diagonal segments are produced by ties

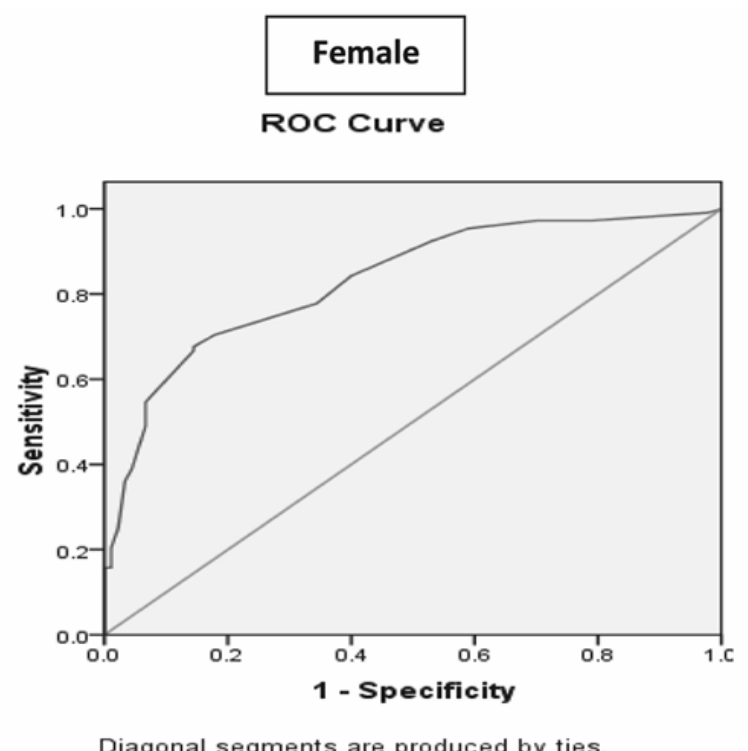

Diagonal segments are produced by ties.

Figure 1. Receiver Operating Characteristics curves (ROC) related to abdominal obesity (waist circumference $\geq 90 \mathrm{~cm} / 80 \mathrm{~cm}$ ) and neck circumference in males and females

\section{Male}

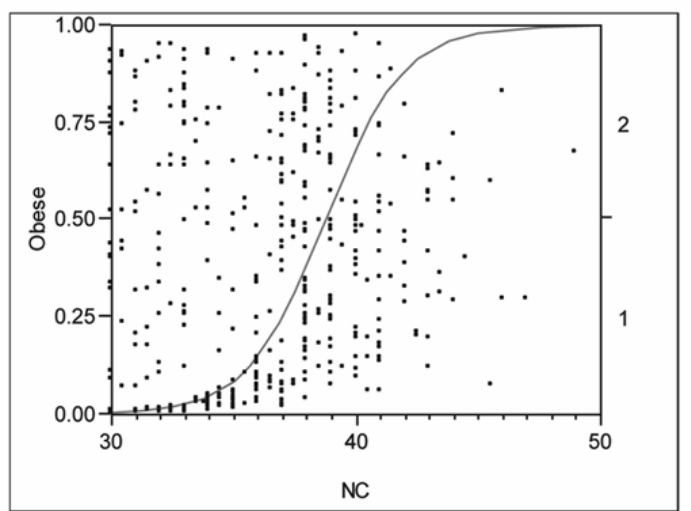

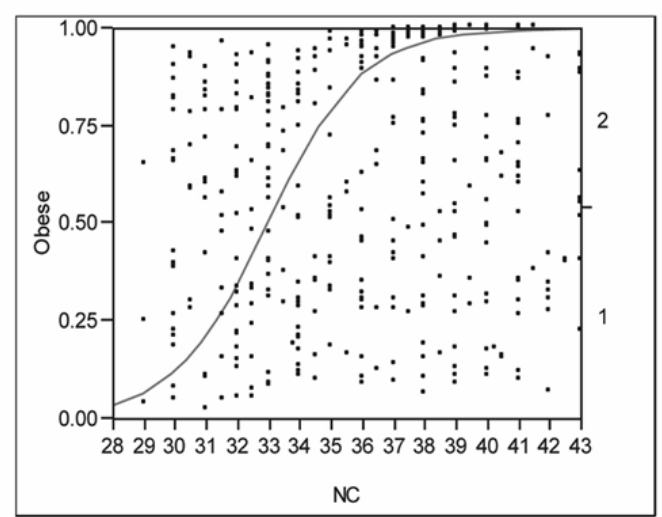

NC

Figure 2. Logistic regression analysis of abdominal obesity by Neck Circumference (NC)

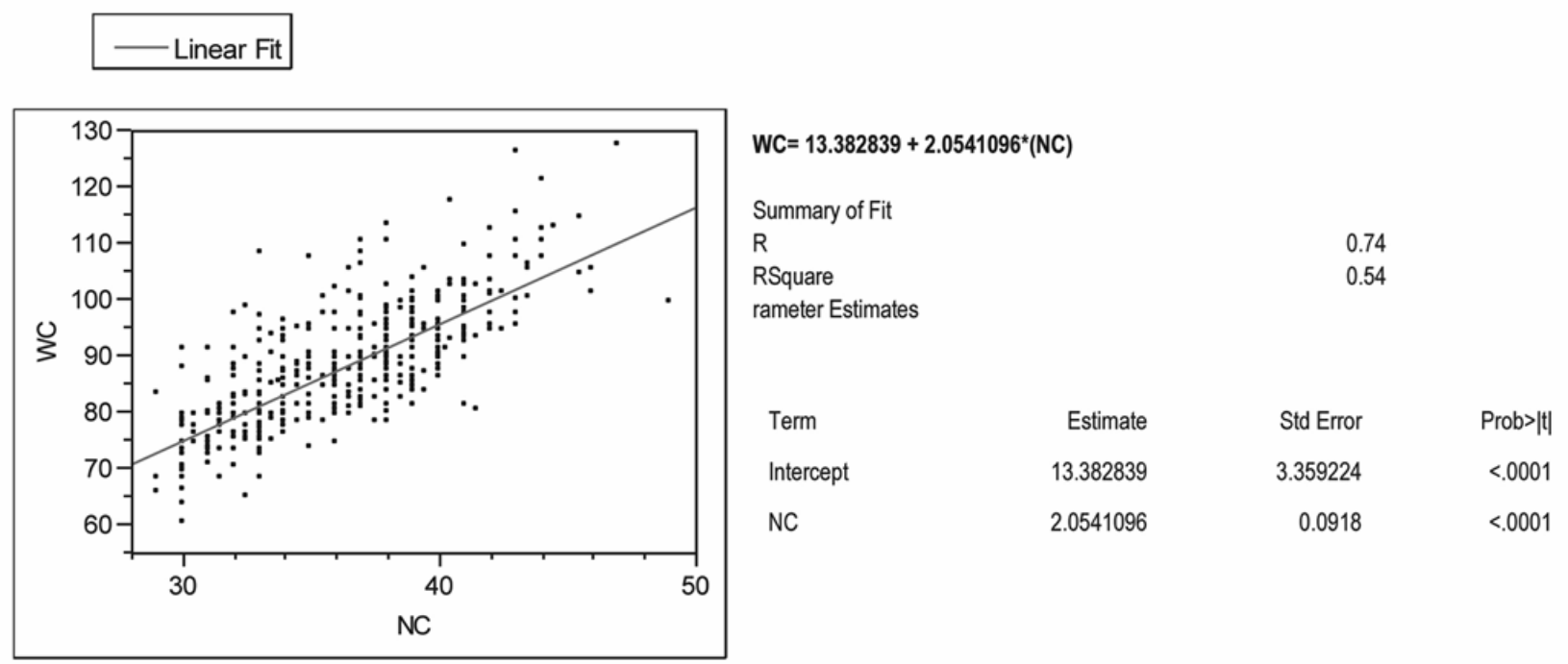

Figure 3. Linear regression analysis of Waist Circumference (WC) by Neck Circumference (NC) 
accuracy of $69.16 \%$ for MS. The chosen cut off level for females of $\geq 33.8 \mathrm{~cm}$ also yielded predictive accuracy of $69.7 \%$ and $75.75 \%$ for both MS and abdominal obesity, respectively. (Table 5) In comparison, waist circumference or abdominal obesity as a predictor of MS has a relatively better sensitivity of $82.6 \%$, and specificity of $64.7 \%$, respectively.

\section{Discussion}

There are various indices that predict specifically intraabdominal fat, cardiovascular risk factors and disease. These include waist:hip circumference ratio (WHR) $)^{5,8}$, waist circumference (WC) $)^{5-6,8-9,11,17-21,1-34}$, abdominal sagittal diameter(SAD) ${ }^{28-29}$, the ratio of waist:thigh circumference ${ }^{25}$. Recently it was shown that WC and SAD show closer association with visceral abdominal adipose tissue accumulation than WHR does. ${ }^{28-29}$ Moreover, the WC and the SAD appeared to be more closely associated with the metabolic variables than the WHR. ${ }^{28}$ They also found out that free fatty acid release from upper body subcutaneous fat was larger than that from lower-body subcutaneous fat, a fact that further strengthens the relevance of measuring upper-body subcutaneous adipose tissue depots. ${ }^{25} \mathrm{WC}$ is therefore widely used as an indirect measure of visceral adipose tissue (VAT); while it is a well-validated anthropometric technique, ${ }^{5-14,17-21,28-34}$ there is high measurement variability which rises with increasing BMI. ${ }^{32}$ On the other hand, BMI predictably correlated with abdominal subcutaneous adipose tissue ASAT $(p=0.002)$ but not VAT nor any index of insulin resistance in a study by Yang and colleagues. ${ }^{32}$

Table 3. Neck Circumference (NC) cut off levels for determining subjects with abdominal obesity [Waist Circumference (WC) of $\geq 90 \mathrm{~cm}$ (males), $\geq 80 \mathrm{~cm}$ (females)] using Receiver Operating Characteristic (ROC) Curve analysis

\begin{tabular}{|c|c|c|c|c|c|c|c|c|c|}
\hline \multicolumn{5}{|c|}{ Males } & \multicolumn{5}{|c|}{ Females } \\
\hline $\begin{array}{l}\text { Cutoff Level } \\
\text { (cm) }\end{array}$ & Sens & Spec & Accuracy & $\begin{array}{c}\text { Youden } \\
\text { index }\end{array}$ & $\begin{array}{l}\text { Cutoff Level } \\
\text { (cm) }\end{array}$ & Sens & Spec & Accuracy & $\begin{array}{c}\text { Youden } \\
\text { index }\end{array}$ \\
\hline . & $0.00 \%$ & $100.00 \%$ & $48.90 \%$ & 0.0000 & & $0.00 \%$ & $100.00 \%$ & $45.45 \%$ & 0.0000 \\
\hline 49 & $0.86 \%$ & $100.00 \%$ & $49.34 \%$ & 0.0086 & 42 & $0.93 \%$ & $100.00 \%$ & $45.96 \%$ & 0.0093 \\
\hline 47 & $1.72 \%$ & $100.00 \%$ & $49.78 \%$ & 0.0172 & 41 & $1.85 \%$ & $100.00 \%$ & $46.46 \%$ & 0.0185 \\
\hline 46 & $3.45 \%$ & $100.00 \%$ & $50.66 \%$ & 0.0345 & 39.5 & $2.78 \%$ & $100.00 \%$ & $46.97 \%$ & 0.0278 \\
\hline 45.5 & $5.17 \%$ & $100.00 \%$ & $51.54 \%$ & 0.0517 & 39 & $6.48 \%$ & $100.00 \%$ & $48.99 \%$ & 0.0648 \\
\hline 44.5 & $6.03 \%$ & $100.00 \%$ & $51.98 \%$ & 0.0603 & 38.5 & $8.33 \%$ & $100.00 \%$ & $50.00 \%$ & 0.0833 \\
\hline 44 & $9.48 \%$ & $100.00 \%$ & $53.74 \%$ & 0.0948 & 38 & $15.74 \%$ & $100.00 \%$ & $54.04 \%$ & 0.1574 \\
\hline 43.5 & $12.07 \%$ & $100.00 \%$ & $55.07 \%$ & 0.1207 & 37.5 & $15.74 \%$ & $98.89 \%$ & $53.54 \%$ & 0.1463 \\
\hline 43 & $20.69 \%$ & $100.00 \%$ & $59.47 \%$ & 0.2069 & 37 & $20.37 \%$ & $98.89 \%$ & $56.06 \%$ & 0.1926 \\
\hline 42.5 & $22.41 \%$ & $100.00 \%$ & $60.35 \%$ & 0.2241 & 36.5 & $25.00 \%$ & $97.78 \%$ & $58.08 \%$ & 0.2278 \\
\hline 42 & $28.45 \%$ & $100.00 \%$ & $63.44 \%$ & 0.2845 & 36 & $36.11 \%$ & $96.67 \%$ & $63.64 \%$ & 0.3278 \\
\hline 41.5 & $30.17 \%$ & $99.10 \%$ & $63.88 \%$ & 0.2927 & 35.5 & $38.89 \%$ & $95.56 \%$ & $64.65 \%$ & 0.3444 \\
\hline 41 & $43.97 \%$ & $97.30 \%$ & $70.04 \%$ & 0.4126 & 35 & $49.07 \%$ & $93.33 \%$ & $69.19 \%$ & 0.4241 \\
\hline 40.5 & $47.41 \%$ & $97.30 \%$ & $71.81 \%$ & 0.4471 & 34.5 & $54.63 \%$ & $93.33 \%$ & $72.22 \%$ & 0.4796 \\
\hline 40.25 & $48.28 \%$ & $97.30 \%$ & $72.25 \%$ & 0.4557 & 34 & $66.67 \%$ & $85.56 \%$ & $75.25 \%$ & 0.5222 \\
\hline$\underline{40}$ & $\underline{62.07 \%}$ & $90.09 \%$ & $\underline{75.77 \%}$ & $\underline{0.5216}$ & $\underline{33.8}$ & $67.59 \%$ & $85.56 \%$ & $\underline{75.76 \%}$ & $\underline{0.5315}$ \\
\hline $3 \overline{9.5}$ & $\overline{63.79 \%}$ & $\overline{88.29 \%}$ & $\overline{75.77 \%}$ & $\overline{0.5208}$ & $\overline{33.5}$ & $\overline{70.37 \%}$ & $\overline{82.22 \%}$ & $\overline{75.76 \%}$ & $\overline{0.5259}$ \\
\hline 39 & $75.86 \%$ & $75.68 \%$ & $75.77 \%$ & 0.5154 & 33 & $77.78 \%$ & $65.56 \%$ & $72.22 \%$ & 0.4333 \\
\hline 38.5 & $77.59 \%$ & $68.47 \%$ & $73.13 \%$ & 0.4605 & 32.5 & $84.26 \%$ & $60.00 \%$ & $73.23 \%$ & 0.4426 \\
\hline 38 & $88.79 \%$ & $49.55 \%$ & $69.60 \%$ & 0.3834 & 32 & $92.59 \%$ & $46.67 \%$ & $71.72 \%$ & 0.3926 \\
\hline 37.5 & $90.52 \%$ & $44.14 \%$ & $67.84 \%$ & 0.3466 & 31.5 & $95.37 \%$ & $41.11 \%$ & $70.71 \%$ & 0.3648 \\
\hline 37 & $95.69 \%$ & $27.03 \%$ & $62.11 \%$ & 0.2272 & 31 & $97.22 \%$ & $30.00 \%$ & $66.67 \%$ & 0.2722 \\
\hline 36.5 & $95.69 \%$ & $22.52 \%$ & $59.91 \%$ & 0.1821 & 30.5 & $97.22 \%$ & $21.11 \%$ & $62.63 \%$ & 0.1833 \\
\hline 36 & $97.41 \%$ & $15.32 \%$ & $57.27 \%$ & 0.1273 & 30 & $99.07 \%$ & $2.22 \%$ & $55.05 \%$ & 0.0130 \\
\hline 35.5 & $97.41 \%$ & $14.41 \%$ & $56.83 \%$ & 0.1183 & 29 & $100.00 \%$ & $0.00 \%$ & $54.55 \%$ & 0.0000 \\
\hline 35 & $97.41 \%$ & $10.81 \%$ & $55.07 \%$ & 0.0822 & 29 & $100.00 \%$ & $0.00 \%$ & $54.55 \%$ & 0.0000 \\
\hline 34.5 & $97.41 \%$ & $7.21 \%$ & $53.30 \%$ & 0.0462 & & & & & 0.0000 \\
\hline 34 & $98.28 \%$ & $5.41 \%$ & $52.86 \%$ & 0.0368 & & & & & 0.0093 \\
\hline 33 & $99.14 \%$ & $1.80 \%$ & $51.54 \%$ & 0.0094 & & & & & 0.0185 \\
\hline 32.5 & $99.14 \%$ & $0.90 \%$ & $51.10 \%$ & 0.0004 & & & & & 0.0278 \\
\hline 31.5 & $99.14 \%$ & $0.00 \%$ & $50.66 \%$ & -0.0086 & & & & & 0.0648 \\
\hline 31 & $100.00 \%$ & $0.00 \%$ & $51.10 \%$ & 0.0000 & & & & & 0.0833 \\
\hline 31 & $100.00 \%$ & $0.00 \%$ & $51.10 \%$ & 0.0000 & & & & & 0.1574 \\
\hline
\end{tabular}

Table 4. Associations of obese by neck circumference with the individual components of Metabolic Syndrome (MS) and Body Mass Index (BMI)

\begin{tabular}{|c|c|c|c|}
\hline & \multicolumn{3}{|c|}{ Obese by neck circumference $($ males $\geq 40 \mathrm{~cm} /$ females $\geq 33.8 \mathrm{~cm}$ ) } \\
\hline & Pearson's Chi- square ( $p$ value) & $95 \% \mathrm{Cl}$ & Odds Ratio Estimate \\
\hline Fasting Triglyceride $\geq 150 \mathrm{mg} / \mathrm{DI}$ & 0.165 & $0.89-2.02$ & 1.34 \\
\hline HDL cholesterol $<40 / 50 \mathrm{mg} / \mathrm{dL}$ & 0.001 & 1.35-3.14 & 2.05 \\
\hline Hypertension $\geq 130 / 85 \mathrm{mmHg}$ & 0.003 & 1.21-2.68 & 1.80 \\
\hline Presence of type 2 Diabetes or FPG $\geq 100 \mathrm{mg} / \mathrm{dL}$ & $<0.001$ & 1.51-3.45 & 2.28 \\
\hline **2 out of 4 components of MS & $<0.001$ & $1.76-3.90$ & 2.62 \\
\hline ** 3 out of 4 components of MS & 0.001 & 1.43-3.90 & 2.36 \\
\hline *MS ( 3 out of 5 components) & $<0.001$ & $3.093-7.227$ & 4.728 \\
\hline Obese by BMI ( BMI $\geq 25$ ) & $<0.001$ & $6.40-16.80$ & 10.38 \\
\hline
\end{tabular}


Table 5. Sensitivity, specificity and predictive accuracy of optimal cut-offs of neck circumference for abdominal obesity and metabolic syndrome

\begin{tabular}{cc}
$\begin{array}{c}\text { Neck Circumference cut off for } \\
\text { males } \geq 40 \mathrm{~cm}\end{array}$ & $\begin{array}{c}\text { Neck circumference cut off for } \\
\text { females } \geq 33.8 \mathrm{~cm}\end{array}$ \\
\hline
\end{tabular}

Sensitivity Specificity Accuracy Sensitivity Specificity Accuracy

For Abdominal Obesity $\geq 90 \mathrm{~cm} / 80 \mathrm{~cm}$

$\begin{array}{llllll}62.07 \% & 90.09 \% & 75.77 \% & 67.59 \% & 85.56 \% & 75.75 \%\end{array}$

For Metabolic Syndrome

$\begin{array}{llllll}57.1 \% & 77.2 \% & 69.16 \% & 75.80 \% & 66.90 \% & 69.70 \%\end{array}$

NC used in combination with other measurements in a three compartment model of interpretable anthropometry separates the effects of visceral adipose tissue mass, subcutaneous tissue mass and subcutaneous adipose tissue distribution on metabolic parameters under crosssectional and longitudinal conditions. ${ }^{24}$ These observations indicate that $\mathrm{NC}$ as an index of upper body fat distribution can be used to identify overweight and obese patients. ${ }^{25,30}$ Moreover, NC was a better direct predictor of visceral adipose tissue area than WC which is in keeping with the previous observation that as BMI increases waist circumference becomes a weaker marker of visceral adipose tissue in markedly obese patients. ${ }^{32-33}$

As main findings in this cross sectional study among high risk Filipino patients admitted in Makati Medical Center, we found that NC cut off levels of $\geq 40 \mathrm{~cm}$ for males and $\geq$ $33.8 \mathrm{~cm}$ for females was well correlated with abdominal obesity (WC $\geq 90 \mathrm{~cm} / 80 \mathrm{~cm}$ ). $\mathrm{NC}$ is a contributing factor to more than half of the variability of waist circumference and has a moderately strong positive linear relationship with waist circumference providing basis for the relationship of neck circumference as a measure for central obesity. NC cut off levels has a high specificity and therefore a high positive predictive value for determining patients with abdominal obesity in both genders, however, with its low sensitivity indices; it has a poor ability to detect patients with abdominal obesity in the general population and therefore will not be a reliable screening measure.

In a similar study by Liubov (Louba) and Laor in a family medicine clinic in Israel in 2001, NC cut off levels of $\geq$ $37 \mathrm{~cm}$ for males and $\geq 34 \mathrm{~cm}$ for females correlated with a higher body mass index BMI. Patients above these levels required a more comprehensive evaluation of their overweight and obesity status. ${ }^{23}$

The Third Report of the National Cholesterol Education Program Expert Panel on Detection, Evaluation, and Treatment of High Blood Cholesterol in Adults highlights the importance of treating patients with MS to prevent cardiovascular diseases. ${ }^{34} \mathrm{~A}$ major contribution of our present report lies in the indication of the association between NC and the factors of the MS. Using NC cut off levels of $\geq 40 \mathrm{~cm}$ for males and $\geq 33.8 \mathrm{~cm}$ for females, a strong association exists between obese by $\mathrm{NC}$ and the individual risk factors of Metabolic Syndrome (MS). Despite NC cut off levels being poor predictors of metabolic syndrome, the significant association between NC and the individual components of MS shows the increased probability or likelihood that patients who are obese by neck circumference will also have high blood pressure, diabetes, low HDL levels and increased abdominal girth.

Our study has shown that the odds of developing hypertension and diabetes among high risk patients are almost doubled with the finding of an enlarged neck. Also the risk of having low-HDL cholesterol is doubled as compared with non-obese (by NC) patients. With these results, the likelihood of satisfying the criteria for MS (3 out of 5) based from the NCEP/ATP III-AHA/NHLBI ${ }^{4}$ is more than quadrupled ( $O R 4.728$, p value $<0.001$ ). In a similar subset of the mentioned group by Liubov (Louba) and Laor, higher NC was found to correlate positively with the factors of the MS. ${ }^{24}$

The result of our study is also supported by the study of Yang and colleagues in 2009 which determined that NC correlated highly with VAT area $(r 2=0.67, \mathrm{p}<0.0001)$ but not with ASAT area indicating that it is both a powerful and selective marker of visceral adiposity. Also it provides further evidence that the cellular programme for laying down cervical adipose tissue is related to intraabdominal fat accumulation. ${ }^{32}$ Furthermore, our data are in keeping with new data from the Framingham Heart Study presented at the recent American Heart Association's Cardiovascular Disease Epidemiology and Prevention annual conference which showed that increasing NC was correlated with increasing FPG and other parameters of the MS. ${ }^{36}$

\section{Limitations and Recommendations}

There are several potential limitations of our study. First, since our study is cross-sectional, we cannot draw conclusions about cause and effect relationships. Second, our research, being a pilot study, has a limited study population. Our study population was limited only to adult high risk urban Filipinos; thus, our results may not be representative of the general population but should apply to this specific sub-set of the Filipino population. Evaluation of neck circumference based on a single measurement might be considered a minor limitation.

From this study, we were able to determine the cut-off values for the neck circumference that correlates with abdominal obesity in adult urban Filipinos at risk for metabolic syndrome and cardiovascular disease. We then recommend that further research, involving large population based studies, be done to validate these findings. Consequently, we hope that the data obtained in this initial investigation be utilized by study groups focusing on obesity and/or metabolic syndrome; and be used in future research re-evaluating recommendations for 
Filipinos at risk for Metabolic Syndrome and abdominal obesity.

\section{Conclusion}

Neck circumference cut off levels of $\geq 40 \mathrm{~cm}$ for males and $\geq 33.8 \mathrm{~cm}$ for females showed a strong correlation with abdominal obesity, as well as with the component risk factors of metabolic syndrome, and therefore is correlated with risk of cardiovascular disease. Above the NC cut off levels, its predictive value for abdominal obesity is high; however, it has a poor ability to detect patients with abdominal obesity in the general population. In view of these findings, the authors cannot recommend the use of neck circumference measurement as a screening test for abdominal obesity in the general population.

\section{Acknowledgment}

We would like to thank all the participants in this study. The paper was a recipient of the PSEM (Philippine Society of Endocrinology and Metabolism)-Merck Research Grant in Diabetes for 2010.

\section{References}

1. American Association of Clinical Endocrinologists (AACE) / American College of Endocrinology (ACE) Statement on the Prevention, Diagnosis, and Treatment of Obesity (1998 Revision). AACE/ACE Obesity Task Force. Endocrine Practice. 1998; 4(5):297-330.

2. Mirmiran $P$, et al. Detection of cardiovascular risk factors by anthropometric measures in Tehranian adults: receiver operating characteristic curve analysis. European Journal of Clinical Nutrition. 2004; 58:1110-1118.

3. Solanzo F. Survey Notes More Obese Filipino Women than Men. www. DOST-FNRI.DOST.GOV.PH. Accessed January 12, 2010.

4. Morales D, MD, Punzalan F, MD, Pacheco E, MD, Sy R, MD. Metabolic syndrome in the Philippine general population: prevalence and risk for atherosclerotic cardiovascular disease and diabetes mellitus. Diabetes and Vascular Disease Research. 2008; 5(1):36-43.

5. Wang F, et al. Waist circumference, Body Mass Index and waist to hip ratio for prediction of the metabolic syndrome in Chinese. Nutrition, Metabolism and Cardiovascular Diseases. October 2009; 19(8):542-547.

6. Beckley, ET. Waist size stronger cardiovascular risk predictor than body mass. Obesity Reviews. July 3, 2002; 3(3):209 - 215.

7. Van Gaal LF, Vansant GA, De Leeuw. Upper body adiposity and the risk for atherosclerosis. IHJ Am Coll Nutr. December 1989; 8(6):504-14.

8. De Koning $\mathrm{L}$, et al. Waist circumference and waist-to-hip ratio as predictors of cariovascular events: Meta-regression analysis of prospective studies. European Heart Journal. 2007; 28: 850-856.

9. Balkau B, Deanfield JE, Després JP, et al. International Day for the Evaluation of Abdominal Obesity (IDEA): A study of waist circumference, cardiovascular disease, and diabetes mellitus in 168,000 primary care patients in 63 countries. Circulation. 2007; 116(17): 1942-51.

10. Yusuf S, Hawken S, Ounpuu S, on behalf of the INTERHEART Study Investigators. Effect of potentially modifiable risk factors associated with myocardial infarction in 52 countries (the INTERHEART study): casecontrol study. Lancet. 2004;364:937-952.

11. Shankuan Z, et al. Waist circumference and obesity-associated risk factors among whites in the third National Health and Nutrition Examination Survey:clinical action thresholds. American Journal of Clinical Nutrition. 2002; 76:743-749.

12. Lapidus L, et al. Distribution of adipose tissue and risk of cardiovascular disease and death: a12 year follow up of participants in the population study of women in Gothenburg, Sweden. British Medical Journal. 1984; 289:1257-1261.

13. Larsson B, et al. Abdominal adipose tissue distribution, obesity and risk of cardiovascular disease and death: 13 year follow up of participants in the study of men born in 1913. British Medical Journal. 1984; 288:1401-1404.

14. Alberti, KGMM, FRCP, Eckel RH, MD, Grundy SM, MD, et al. Harmonizing the Metabolic Syndrome-A joint Interim Statement of the International Diabetes Federation Task Force on Epidemiology and Prevention; National Heart, Lung, and Blood Institute; American Heart Association; World Heart Foundation,; International Atherosclerosis
Society; and International Association for the Study of Obesity. Circulation. 2009; 120:1640-1645.

15. Eckel RH, Grundy SM, Zimmet PZ. The metabolic syndrome. Lancet 2005; 365(9648):1415-1428

16. The IDF consensus worldwide definition of the metabolic syndrome www.idf.org/webdata/docs/IDF_Metasyndrome_definition.pdf. Accessed January 12,2010

17. Chaoyang $\mathrm{L}$, et al. Increasing trends in waist circumference and abdominal obesity among U.S. adults. Obesity. January 2007; 15(1):216223.

18. Wang W, et al. Prevalence of metabolic syndrome and optimal waist circumference cut-off points for adults in Beijing. Diabetes Research and Clinical Practice. 2010; 4718:1-8.

19. Sang Yeoup L, et al. Appropriate waist circumference cutoff points for central obesity in Korean adults. Diabetes Research and Clinical Practice. 2007; 75: 72-80.

20. Yuqian B, et al. Optimal waist circumference cutoffs for abdominal obesity in Chinese. Atherosclerosis. 2008; 201: 378-384

21. Janssen, I., et al. Waist circumference and not Body Mass Index explains obesity-related health risk. American Journal of Clinical Nutrition 2004; 79: 379-384.

22. Ben-Noun L, Laor A. Relationship between changes in neck circumference and changes in blood pressure. American Journal of Hypertension. May 2004; 17: 409-414.

23. Ben-Noun L and Laor A. Relationship of neck circumference to cardiovascular risk factors. Obesity Research. 2003; 11:226-231.

24. Ben-Noun L, Sohar E, Laor A. Neck circumference as a simple screening measure for identifying overweight and obese patients. Obesity Research. August 2001; 9(8):470-477.

25. Sjo stro"m CD, Håkangård AC, Lissner L, Sjo"stro“m L. Body compartment and subcutaneous adipose tissue distribution- risk factor patterns in obese subjects. Obesity Research. 1995; 3:9-22

26. Salomon, Eddelyn, Hizon, Ma. Christina and Raboca, Josephine. Minimum waist circumference and visceral fat values by ultrasonography to identify adult urban Filipino patients at risk for Metabolic Syndrome. PJIM. 2011; 49-1:15-21.

27. Inove $\mathrm{S}$, Zimmet $\mathrm{P}$, et al. The Asia-Pacific perspective: Redefining obesity and its treatment. International Association for the Study of Obesity. February 2000; 8-55.

28. Turcato, E, et al. International waist circumference and abdominal sagitta diameter as surrogates of body fat distribution in the elderly: Their relation with cardiovascular risk factors. Journal of Obesity. 2000; 24: 1005-1010.

29. Pouliot MC, Despre's JP, Lemieux S, Moorjani S, Bouchard C, Tremblay A Waist circumference and abdominal sagittal diameter: Best simple anthropometric indexes of abdominal visceral adipose tissue accumulation and related cardiovascular risk in men and women. American Journal Cardiology. 1994;73: 460-468

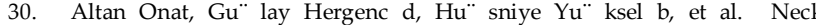
circumference as a measure of central obesity: Associations with metabolic syndrome and obstructive sleep apnea syndrome beyond wais circumference. European Society for Clinical Nutrition and Metabolism. 2009; 28:46-51.

31. Han TS, et al. Waist circumference action levels in the identification of cardiovascular risk factors: prevalence study in a random sample. British Medical Journal. 1995; 311:1401-1405.

32. Yang L, Samarasinghe YP, Kane L, et al. Visceral adiposity is closely correlated with neck circumference and represents a significant indicator of insulin resistance in WHO grade III obesity. Clinical Endocrinology. "Accepted Article"; doi: 10.1111/j.1365-2265.2009.03772.x

33. Han TS, Sattar N, Lean M. Assessment of obesity and its clinical implications. British Medical Journal. 2006; 333:695-698.

34. National Institutes of Health (NIH), National Heart, Lung, and Blood Institute (NHLBI). Clinical guidelines on the identification, evaluation and treatment of overweight and obesity in adults: the evidence report. Obesity Research. 1998; 6(2):51S-209S

35. National Institutes of Health. Third Report of the National Cholestero Education Program Expert Panel on Detection, Evaluation and Treatment of High Blood Cholesterol in Adults (Adult Treatment Panel III). Bethesda MD: National Institutes of Health; September 2002; 02-5215: 1-284.

36. O'Donnell, CJ. Progress and Promise of Genome-wide Association Studies for Cardiovascular Disease, NHLBI Framingham Heart [oral presentation] AHA 49 th Cardiovascular disease prevention and epidemiology conference. March 12, 2009. 